\title{
RESEARCH ON LOW CARBON FINANCIAL SUPPORT STRATEGIES FROM THE PERSPECTIVE OF ECO-ENVIRONMENTAL PROTECTION
}

\begin{abstract}
This paper provides an in-depth analysis and research on low carbon financial support strategies from the perspective of ecological environmental protection. The understanding and analysis of the development status of ecological environmental protection inspectors, the analysis of the current rule of law construction, organizational structure, operation mechanism and capacity of the current ecological environmental protection inspectors, the understanding of the defects and problems in the work of the inspectors, to provide a basis for improving the inspection function. Through financial instruments It is of great theoretical value and practical significance to realise the full utilization of resources, the optimization of industrial structure and the low-carbon cycle development of agricultural economy. Combining the current situation and constraints of financial support for low-carbon agriculture, we propose targeted financial policy recommendations such as credit innovation for agricultural green projects rich in characteristics and conducive to the development of low-carbon agriculture, broadening private financing channels for low-carbon agriculture, and exploring low-carbon agricultural insurance. The entropy value method is used to determine the index weights, and the comprehensive evaluation method is used to calculate the comprehensive development evaluation value of the two subsystems; finally, the coupling coordination degree model is used to analyse the coupling degree and coupling coordination degree of the carbon finance and low-carbon agriculture composite systems, and the factors affecting the coupling coordination degree are analysed on this basis. Although the coupling level between them is at a low level of coupling, it is in transition to a medium coupling; the coupling coordination degree is at a mild disorder, and gradually in transition to a near disorder.
\end{abstract}

Keywords: ecological environment, conservation perspective, low carbon financial support, strategy research

\section{Introduction}

With the continuous development of the social economy and the further increase of people's consciousness, the western government began to change its direction from economic control to social control, and the scholars of control theory also turned the centre of their research to this direction, opening new fields in theoretical research [1]. The concept of social regulation defined by Samuelson explicitly includes the protection of the environment; Uekusa Yoshi defines social regulation in more detail and points out that government regulation should provide standards and prohibit specific behaviours: Professor Cheng Qizhi believes that social regulation refers to the administrative government, to protect the health and safety of consumers, workers, and the public, and the quality of life, and in a certain legal and regulatory framework, to impose such measures as the regulation of enterprises [2]. To protect the health and safety of consumers, workers, and the public, as

\footnotetext{
${ }^{1}$ Chongqing Vocational Institute of Engineering, Chongqing, 402260, China, email: jianglihong202107@163.com, ORCID: 0000-0002-2298-3621
} 
well as the quality of life, the administrative government, under the framework of laws and regulations, controls the behavior of enterprises that cause negative internalities, such as product quality, workplace quality, and negative externalities, such as environmental pollution [3]. However, after nearly 40 years of development, although the discipline has developed rapidly and with rich achievements, it is still immature, as evidenced by the fact that some basic concepts and theories are still widely divergent, especially the research on social control is relatively weak.

As a new exploration of China's environmental protection work, the eco-environmental protection inspection system has achieved fruitful results in the past three years, gaining a lot of practical experience and training many inspectors, but still stumbling in the combination of practice and management theory [4]. On the other hand, there are too few research talents in the environmental protection system for management, and although management scholars have studied more environmental protection issues, few of them are dedicated to long-term environmental protection [5]. The current environmental protection inspections rely more on internal party regulations as guidance, and some rules and regulations are only promulgated as work progresses, which makes it difficult for researchers to grasp the direction and start. Most importantly, the current environmental protection inspectors rely more on party regulations for guidance, and some of the rules and regulations are promulgated as the work progresses, which makes it difficult for researchers to grasp the direction and start [6].

The development of new urbanization needs a large amount of capital, but over-reliance on financial allocation, local government financing pressure, and limited capacity; while financial institutions have poor interest in the construction of new urbanization and poor integration of social capital, which makes the capital demand for new urbanization cannot be effectively supplied. At present, there are still many problems in the financial support system for the development of new urbanization in China, such as imperfect financial support organization system. The current financial support system for the development of new urbanization in China still has many problems, such as imperfect financial support organization system, low ratio of direct financing, slow development of venture capital and angel investment, imperfect credit guarantee system and financial legal system, etc. Therefore, it is very important to reform the financial support system for new urbanization. An empirical study is conducted at national and provincial levels on the mechanism of interaction between new urbanization and financial support, and through the analysis of development obstacles, feasible strategies for reforming the financial support system are proposed to solve various problems encountered in the development of new urbanization. Most scholars have given weak implement ability recommendations and have not systematically and purposefully conducted barrier analysis based on empirical results to propose more feasible financial support reform strategies. This paper will draw on and summarise the research experience of previous scholars, and then combine it with our theoretical thinking and empirical research, and strive to make a breakthrough in the following aspects. First, through theoretical combing, we will analyse the mechanism of their interaction in depth from multiple angles and levels and then propose feasible reform strategies systematically through the analysis of development obstacles based on empirical evidence of their interactive development. 


\section{Methods and materials}

Through a comparative analysis of the global forest area data from 2010 to 2019, the global forest area is generally decreasing, and the global forest resources are facing a crisis. In 2010, the global forest area was 3.841 billion hectares, and by 2019 it was 3.825 billion hectares [7-17]. As time goes by, global forest resources continue to decrease. By the end of 2018, the world's total forest area accounted for approximately $25.60 \%$ of the world's total land area. The total global forest NPP (vegetation net primary productivity) is about $55.44 \%$. From 2000 to 2018, the global forest coverage area decreased by 247 million $\mathrm{m}^{2}$, a net decrease of 17 million $\mathrm{m}^{2}$, and the net reduction accounted for $0.44 \%$ of the global forest area. According to the global ecological environment remote sensing monitoring statistics of the Ministry of Science and Technology, the global forest NPP caused by deforestation and afforestation has dropped by 59 million.

With the deepening of the administrative reform, the "three programs" (i.e., function configuration, internal organization, and staffing regulations) of the Provincial Department of Ecology and Environment were formally introduced, making it clear that undertaking the work of provincial ecological environmental protection inspectors is an important function of the six regional inspection offices. There is no systematic and targeted analysis of obstacles based on empirical results, to put forward more feasible financial support reform strategies. This article will draw on and summarise the research experience of previous scholars, combined with my own theoretical thinking and empirical research, and strive to make breakthroughs in the following aspects. The regional ecological environmental protection inspection system faces some problems in actual operation, such as some of the functions of the regional inspection offices overlap with the functions of the provincial department's enforcement bureau. When the enforcement bureau found the same type of illegal facts in many enterprises, it also had to further request the implementation of the responsibility of the competent department, and this process of implementing the department's responsibility is supervising the government [18]. The actual regular inspection functions and powers of the regional ecological environmental protection inspectors are very limited. On the one hand, the regional inspection offices perform their functions mainly based on internal documents of the Department of Ecology and Environment, and their inspection powers have not yet been recognised by the Environmental Protection Law and other national laws; on the other hand, the regional inspection offices are only internal offices of the Department of Ecology and Environment, and are full divisional level units, which in practice only have inspection powers, reporting powers, limited investigation and supervision powers, and no actual enforcement and punishment powers for environmental violations found by the inspectors, lacking the corresponding means of restraint, as shown in Figure 1.

Coordination refers to the high degree of correlation between multiple systems or elements and is based on respect for objective laws, focusing on the connection between things, reflecting the ideal state of things and the process of achieving that ideal state. Coordination has a slightly different focus in different disciplines, for example, in the field of management, it focuses on the means and process of achieving management goals by integrating various management elements, while in the field of economics, it is the process of bringing a system to equilibrium through the action of various economic forces, 
but the general idea is the same, that is, to achieve the desired human purpose through development [19].

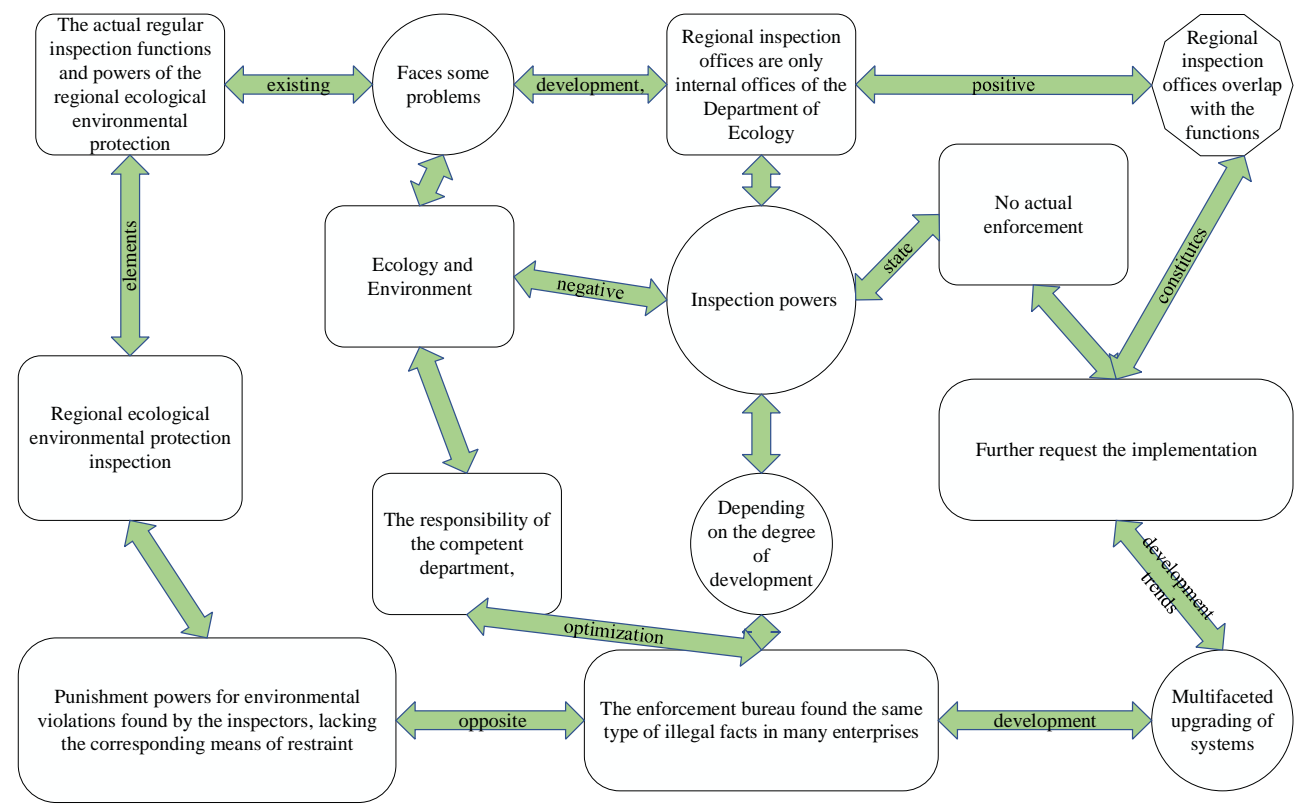

Fig. 1. Framework of ecological and environmental protection perspective

The primary significance of carbon finance in supporting the development of low-carbon agriculture is that it can promote the formation of low-carbon capital, i.e., carbon finance can effectively absorb a large amount of idle capital in the society, forming a large-scale savings capital resource, which can be converted into low-carbon capital for the development of low-carbon agriculture in the real economy through the optimal allocation of financial intermediaries. The development of low-carbon agriculture requires a large amount of capital investment, while the industrialization of a low-carbon technology will bring high return income. Therefore, with the help of carbon finance, innovative financing methods for low-carbon agriculture, the creation of low-carbon agricultural derivatives, low-carbon agricultural insurance, low-carbon agricultural securities, low-carbon agricultural bonds, or financial products related to low-carbon agriculture can broaden the channels for the public to participate in low-carbon agricultural investment, promote the prosperity of the low-carbon agricultural investment and financing market, and expand the scale of funds involved in low-carbon agricultural investment, which can better solve the problem of funds required for the development of low-carbon agriculture. The problem of funds was shown in Figure 2.

Land degradation is one of today's serious ecological crises. The over-utilization and inappropriate development of land caused by economic, political, cultural, and other factors have led to the emergence of land erosion, salinization and even land desertification. Through the analysis of global land degradation and improvement and restoration data from 2000 to 2018, land degradation and improvement are a relatively balanced development on 
a global scale. The total land area of land degradation and aggravation on all continents has increased $16,095,900 \mathrm{~km}^{2}$, accounting for $11.95 \%$ of the world's total land area, while the total area of improved and restored land is 16.4762 million $\mathrm{km}^{2}$, accounting for about $12.23 \%$ of the world's total land area. The two are basically the same, and the area of improvement is larger. However, judging from the specific conditions of each continent, land degradation presents a serious regional imbalance.

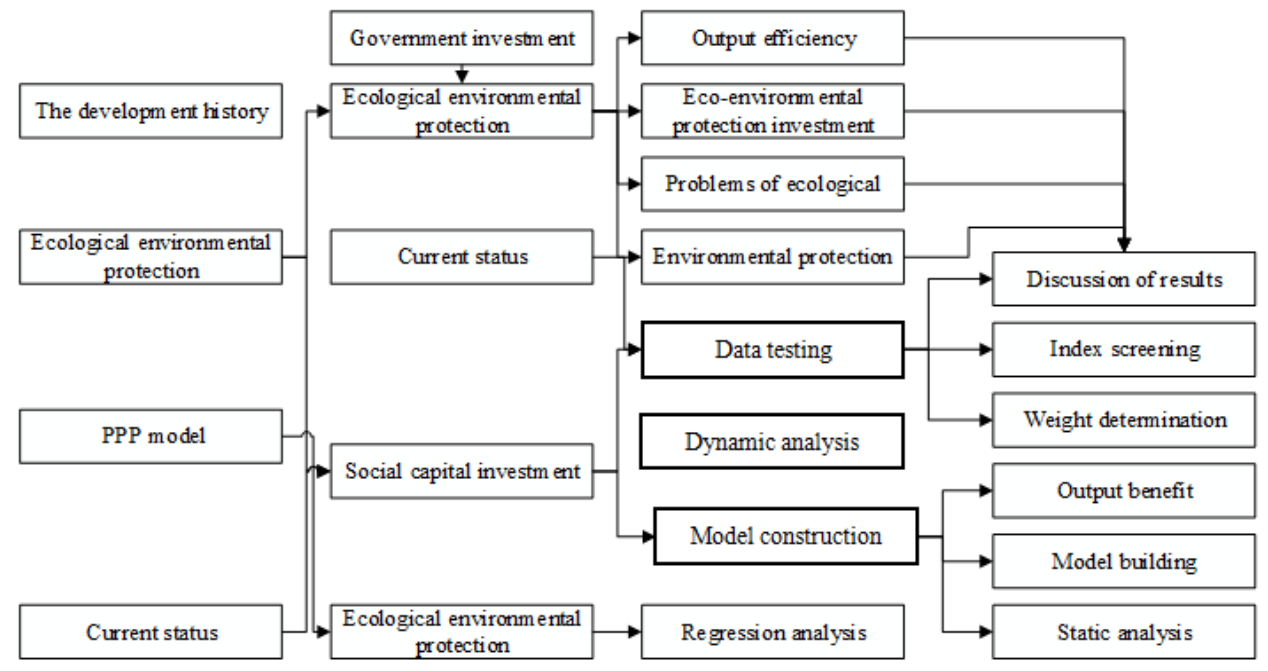

Fig. 2. Research framework

After a low-carbon agricultural technology is developed successfully, it needs to be put into the market to realise the technology transformation. However, it is impossible to predict how much a low-carbon agriculture technology should cost and what the future returns will be. Therefore, investors need to collect relevant information, study the market situation, and build models to predict future development, which requires a large investment in information upfront, thus increasing the cost of low-carbon agricultural technology promotion. The carbon finance market is an effective place for information integration, with the function of information collection and processing, and can make a relatively accurate assessment of the prospect of low-carbon project technology promotion. Technology introduction and independent innovation in developed regions can significantly increase carbon emissions. Imitation innovation has a significant effect on carbon emissions, while the western region is not significant. Therefore, we can use the carbon financial market to support the development of low-carbon agriculture.

The comprehensive utilization of solid waste, sulphur dioxide removal, smoke (dust) removal and wastewater treatment are selected to measure the industrial pollution treatment, because the removal and treatment data are missing, and to some extent, the specific emissions of industrial pollutants at this stage can reflect the results and benefits of environmental pollution treatment within a certain period, such as efficient treatment of pollutant emissions will naturally reduce, so emissions can indicate the treatment situation. 
Therefore, the industrial pollution situation is measured by its emission instead of removal, as shown in Table 1.

Table 1

Accounting method of ecological resource loss and environmental pollution system

\begin{tabular}{|c|c|c|c|c|}
\hline Angle & Dimension & Specific indicators & Calculation method & Variable \\
\hline \multirow{5}{*}{ Invest in } & Energy use & $\begin{array}{c}\text { Energy consumption per } \\
\text { unit of GDP }\end{array}$ & Total energy consumption/GDP & X1 \\
\cline { 2 - 6 } & Capital investment & \begin{tabular}{c} 
Pollution control \\
investment intensity \\
\cline { 2 - 6 }
\end{tabular} & $\begin{array}{c}\text { Total investment in } \\
\text { environmental pollution } \\
\text { control/GDP }\end{array}$ & X2 \\
\hline \multirow{3}{*}{ Output } & $\begin{array}{c}\text { Nechnology } \\
\text { investment }\end{array}$ & Number of employees & $\begin{array}{c}\text { Number of employed persons in } \\
\text { urban units }\end{array}$ & X4 \\
\cline { 2 - 6 } & Industrial pollution & R\&D investment intensity & R\&D expenditure/GDP & X5 \\
\cline { 2 - 6 } & Life pollution & Technician input & $\begin{array}{c}\text { Full-time equivalent of R\&D } \\
\text { personnel }\end{array}$ & X6 \\
\hline
\end{tabular}

It represents the results of regression analysis of environmental protection investment environment output, government fiscal expenditure and social capital investment under the random effect model and the fixed effect model. It can be seen that the $t$ statistic values of the regression coefficients of the constant term, government fiscal expenditure and social capital investment in the random effects model are all greater than 2 , and the $P$ values corresponding to the regression coefficients of these three variables are all less than 0.01 , which means that in $1 \%$ under the confidence level, the regression coefficients of government fiscal expenditure and social capital investment in Shaanxi Province's ecological and environmental protection are significant; while the $t$ statistic values of the coefficients of government fiscal expenditure and social capital investment in the fixed-effect model are all less than 2, and these three variables are regression. Many regional environmental problems have been solved. However, due to many restrictions such as functional attributes, administrative levels, and legal recognition, the six regional inspection offices that assume the function of regional inspections have long suffered from insufficient authority and limited control methods. The $P$ values corresponding to the coefficients are all greater than 0.1 , which shows that the regression coefficients of government fiscal expenditure and social capital investment for ecological and environmental protection in Shaanxi Province are not significant at the $10 \%$ confidence level. In addition, the F-Statistic of the random effects model is 12.809 , which is greater than the critical value in the F distribution table at the $1 \%$ confidence level, which shows that the environmental output of the ecological environmental protection investment in Shaanxi Province and the government fiscal expenditure and social capital investment. The random effects model of is significant at the $1 \%$ confidence level. In summary, under the random effects model, Shaanxi government fiscal expenditure and social capital investment have a significant correlation to the environmental output of ecological and environmental protection investment.

The low carbon economic development model means that the theory of low carbon economy is used as a prerequisite to carry out various economic activities, and the current technical means of carbon reduction and emission reduction allow the traditional economic development model to be transformed into a green economic development model. 
Coordination in different disciplines has slightly different emphasis on its meaning. For example, coordination in the field of management focuses on the means and processes of comprehensively considering various management elements to achieve management goals. The low carbon economy emphasises the concept and practice that this economic development model is an important tool for regional agricultural economic development. Therefore, low-carbon economic theory is the fundamental theoretical basis for financial instruments to support the development of low-carbon agriculture. Low-carbon economic development is an important measure of financial instruments to support low-carbon agricultural development [20].

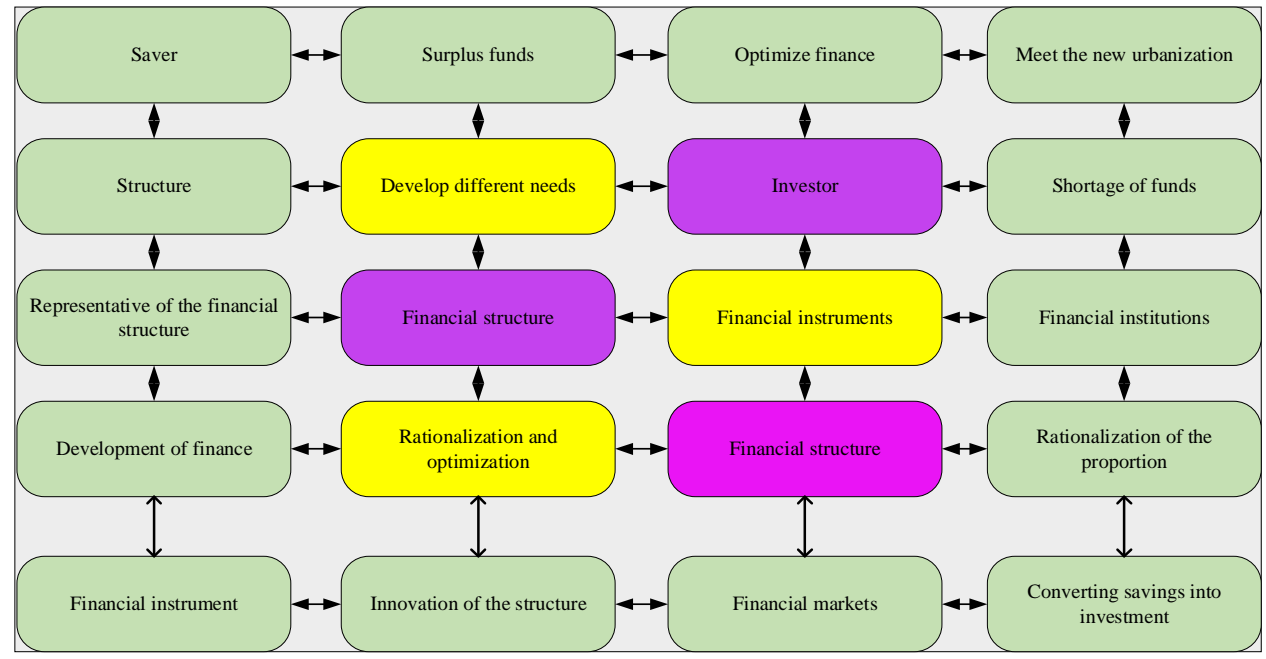

Fig. 3. Mechanism of the role of financial support structure on a new urbanization

According to Goldsmith, the representative of the financial structure theory, the financial structure is composed of the financial instruments and financial institutions that a country. The development of finance is based on the rationalization and optimization of the financial structure, i.e., the rationalization of the proportion of each financial sector and financial instrument, the innovation of the structure of financial markets, institutions, and instruments, and the gradual upgrading from the lower to the higher level. Firstly, the financial structure affects the intensive urban development by influencing the ratio and way of converting savings into investment; the rich connotation of new urbanization requires diversification of investment subjects and varieties, and the optimization of financial structure helps to meet the diversified investment and financing needs of new urbanization. The carbon finance market also effectively manages the risk of low-carbon technology research and development through the development of various carbon financial derivatives, hedging of carbon emission rights trading, risk hedging, and risk transfer. Secondly, Northam's S-type theory points out that there are stage characteristics of urbanization development, and the needs arising from population transfer, industrial transformation, public service upgrading, and investment and financing at different stages are different, and the corresponding financial support needs should also be flexible, i.e., the financial 
structure should fully adapt to and meet the stage demands of urbanization, as shown in Figure 3.

The efficiency of financial support is usually measured by the ratio of savings into investment, mainly by changing the structure of capital allocation, which in turn leads to an improved production structure, enabling capital to be optimally allocated and its marginal productivity to be significantly increased.

For example, to mitigate losses from inflation, financial institutions can be used to absorb idle funds; financial institutions can perform portfolio optimization by assessing investors' risk-return preferences; and to improve the returns of economic participants, the risk diversification function of financial markets can be used, for example, by selling financial instruments such as stocks or funds to meet liquidity needs. To alleviate the losses caused by inflation, financial institutions can be used to absorb idle funds; financial institutions can optimise investment portfolios by evaluating investors' risk-return preferences; to increase the returns of economic participants. Through the optimal allocation of capital, funds are effectively allocated to urbanization construction projects with the highest marginal efficiency of capital, which improves the speed and efficiency of rural-urban transfer and makes the supply of funds for new urbanization more adequate and efficient, as shown in Table 2.

Table 2

Index system of factors affecting environmental pollution control efficiency

\begin{tabular}{|c|c|c|c|}
\hline Influencing factors & Indicator picker & Calculation method & Explanation \\
\hline $\begin{array}{c}\text { The level of economic } \\
\text { development }\end{array}$ & GDP per capita & $\begin{array}{c}\text { Gross Regional } \\
\text { Product/Number of } \\
\text { People }\end{array}$ & $\begin{array}{c}\text { GDP (Gross } \\
\text { Domestic } \\
\text { Product) }\end{array}$ \\
\hline Industrial structure & $\begin{array}{c}\text { The proportion of } \\
\text { secondary industry in GDP }\end{array}$ & $\begin{array}{c}\text { Secondary industry } \\
\text { added value/GDP }\end{array}$ & $\begin{array}{c}\text { INS (Industrial } \\
\text { structure) }\end{array}$ \\
\hline Financial development & $\begin{array}{c}\text { Financial industry value } \\
\text { added }\end{array}$ & $\begin{array}{c}\text { Financial industry value } \\
\text { added }\end{array}$ & $\begin{array}{c}\text { FD (Financial } \\
\text { development) }\end{array}$ \\
\hline Technique level & $\begin{array}{c}\text { R\&D expenditure input } \\
\text { intensity }\end{array}$ & R\&D expenditure/GDP & $\begin{array}{c}\text { RD (Research and } \\
\text { Development) }\end{array}$ \\
\hline $\begin{array}{c}\text { Openness to the outside } \\
\text { world }\end{array}$ & $\begin{array}{c}\text { Percentage of total foreign } \\
\text { investment }\end{array}$ & $\begin{array}{c}\text { FDI (Foreign } \\
\text { Direct } \\
\text { Investment) }\end{array}$ \\
\hline
\end{tabular}

The consumption of large amounts of fossil fuels has brought about an increase in greenhouse gas emissions such as carbon dioxide, triggering the frequent occurrence of environmental pollution phenomena such as acid rain and the greenhouse effect. From 2010 to 2020, energy consumption increased from $9.1 \%$ to about $20 \%$ of the global share, carbon dioxide emissions increased from $12.9 \%$ to about $23 \%$, per capita carbon dioxide emissions have exceeded the world average [21]. The world's largest greenhouse gas emitter, the realization of low-carbon economic development is a long way to go. From the main measures and characteristics of China's environmental pollution management, China's environmental pollution management has roughly gone through four stages.

\section{Analysis of results}

The R\&D of low-carbon agricultural technology is full of uncertainty due to liquidity risk and yield risk, and the $R \& D$ of low-carbon agricultural technology requires a large 
amount of capital, which cannot be solely financed by internal financing, and investors are normally risk-averse, so they are less willing to invest in the high-risk R\&D projects of low-carbon agricultural technology. The carbon finance market also effectively controls the risk of low-carbon technology through the development of various carbon finance derivatives, hedging, risk hedging, and risk transfer of carbon emissions trading. Therefore, we can learn from this experience and develop derivatives related to low-carbon agricultural technology to transfer and control the risk of low-carbon agricultural technology $R \& D$ and promote low-carbon agricultural technology $R \& D$, as shown in Figure 4 .

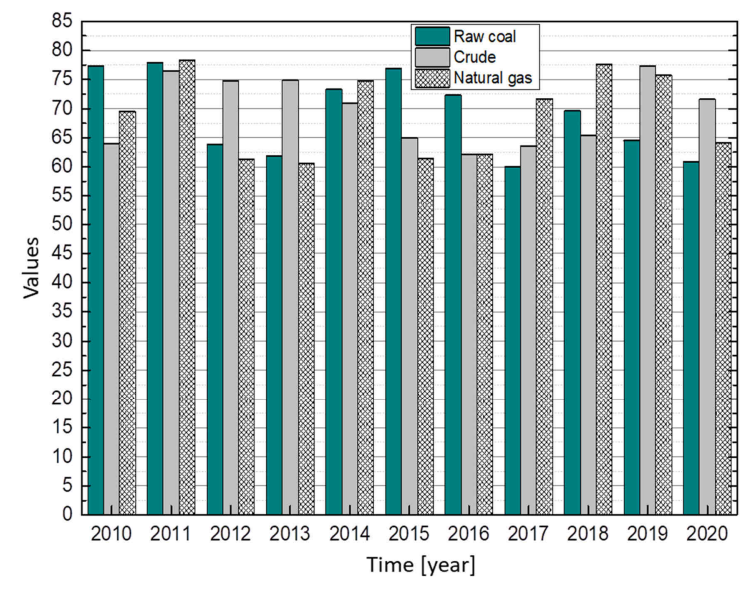

Fig. 4. Energy consumption data; The values of the vertical coordinates in the graph represent: Raw coal [billion tonnes], Crude [Ten million tonnes], Natural gas [billion $\mathrm{m}^{3}$ ]

From the above analysis, we can see that China's energy consumption is mainly based on fossil fuels such as coal, and the rapid economic growth is built based on massive consumption of primary energy.

Financial investment is an important support for environmental pollution management, the effective financial means to manage environmental pollution is concentrated in the investment in environmental pollution management. The main body of investment in environmental pollution control in China is mainly the government, and the total investment by enterprises is less than $10 \%$ of the total government investment. Low-carbon agricultural bonds or low-carbon agriculture-related financial products, broaden the channels for the public to participate in low-carbon agricultural investment, promote the prosperity of the low-carbon agricultural investment and financing market, and expand the scale of funds to participate in low-carbon agricultural investment, which can better solve low-carbon. The issue of funds needed for agricultural development. As shown in Figure 5, since 2010, the proportion of investment in environmental pollution control as a percentage of GDP is generally decreasing trend, investment efforts gradually reduced, the total investment in environmental pollution control overall upward trend, indicating that the investment in environmental pollution control and the national economic development level has not improved simultaneously, in the current level of economic development should further enhance the investment in environmental pollution control. 


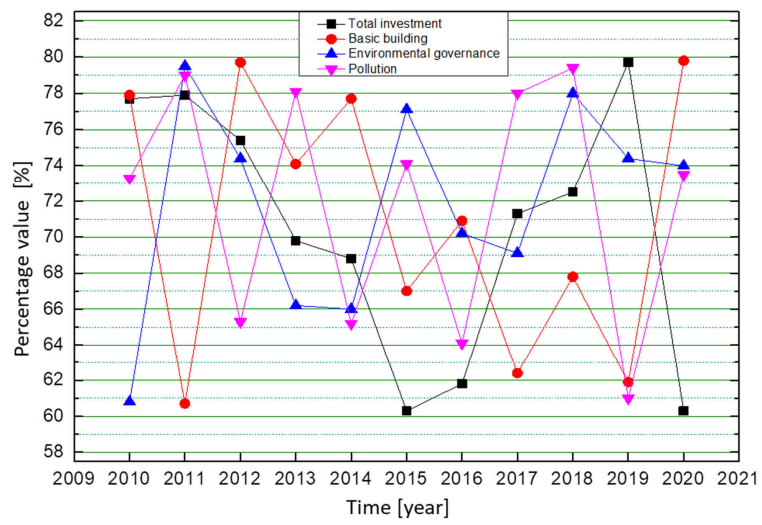

Fig. 5. Investment in environmental pollution control

Figure 5 shows the results of regression analysis of economic output, government fiscal expenditure and social capital investment of Shaanxi Province's ecological environmental protection investment from the perspective of PPP (Public-Private Partnership) under the random effect model and the fixed effect model. Figure 5 shows that the $t$ statistic values of the regression coefficients of the constant term and social capital investment in the random effects model are both greater than 2, and the $P$ values of the regression coefficients of the constant term and social capital investment are both less than 0.05 , which shows that the $5 \%$ confidence. The regression coefficient of the constant term and social capital investment is significant at the level. Although the $t$ statistic value of the regression coefficient of government fiscal expenditure is less than 2, the value of $P$ is less than 0.1 , which shows that under the $10 \%$ confidence level, the ecological environment protection investment economy of Shaanxi Province. The regression coefficients of output and government fiscal expenditure and social capital investment are significant; in the fixed effects model, only the constant term regression coefficient has a $t$ statistic greater than 2 . The proportion of carbon dioxide emissions has increased from $12.9 \%$ to about $23 \%$, and the per capita carbon dioxide emissions have exceeded the world average level. It has become the world's largest emitter of greenhouse gases, and there is a long way to go to achieve low-carbon economic development. The $t$ statistic values of the regression coefficient of government fiscal expenditure and social capital investment are both. It is less than 2, and the $P$ value of the regression coefficients of government fiscal expenditure and social capital investment is greater than 0.1 , which shows that the regression coefficient of economic output of Shaanxi Province's ecological environmental protection investment and government fiscal expenditure and social capital investment is at a confidence level of $10 \%$. Not obvious. In addition, the F-Statistic of the random effects model is 2.478 , which is greater than the critical value in the $\mathrm{F}$ distribution table at the $10 \%$ confidence level, which indicates the random effects of eco-environmental protection investment, economic output, government fiscal expenditure, and social capital investment. The model is significant at the $10 \%$ confidence level. In summary, under the random effects model, government fiscal expenditure and social capital investment have a significant correlation with the economic output of ecological and environmental protection investment. 
According to the results of measurement, each index value is divided into three levels: high, medium, and low; efficiency index value less than 1 is low, efficiency index value equal to 1 is medium, and efficiency index value greater than 1 is high. The technical progress index, scale efficiency change index, and total factor productivity index is relatively effective as a whole, except for Inner Mongolia and Guizhou provinces, the technical progress index, scale efficiency change index, and total factor productivity index are all higher than 1 in other 28 provinces; the pure technical efficiency of each province is mostly at a medium stable level, Hubei, Shaanxi, and Gansu are at a high level, and Jiangxi and Anhui are at a low level; the technical efficiency change. According to the previous theory, this article believes that the improvement of environmental pollution control efficiency requires the participation of social macro and micro subjects including the government. Therefore, the number of labourers can measure the labour input of environmental pollution control to some extent. The distribution of the technical efficiency change index is similar to that of the pure technical efficiency index, with all provinces except Fujian, Jiangxi, and Anhui being at medium to high levels. Overall, the efficiency of environmental pollution control has been high since 2010. From a regional perspective, the overall trends of the pure technical efficiency change index and technical efficiency change index are roughly the same, while the overall trends of the technical progress index and scale efficiency are roughly the same and differ significantly from province to province. The polarization of the total factor productivity index is more obvious, which shows that there are some regional differences in the efficiency of environmental pollution control in China, and it is necessary to pursue a high level of development based on balanced development, as shown in Figure 6.

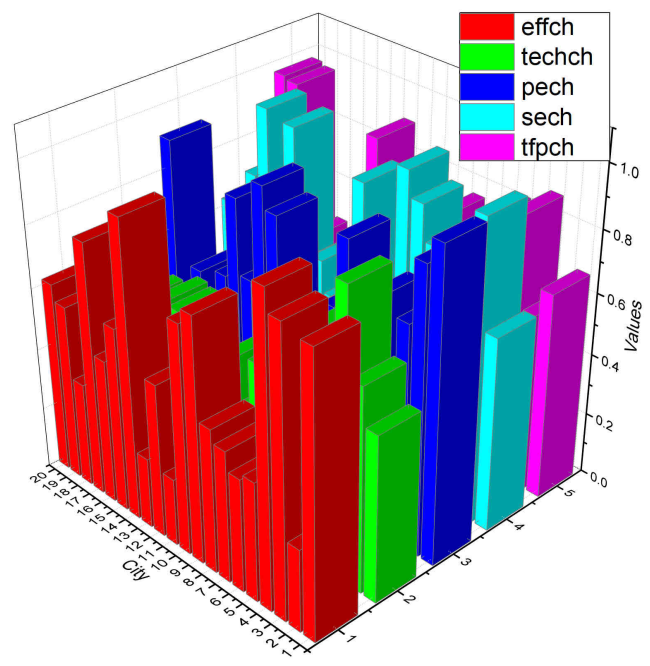

Fig. 6. Trend of Malmquist index: effech: Technical efficiency; sech: Scale efficiency change index; techch: Technical efficiency change index; pech: Pure technical efficiency change index; tfpch: Total factor productivity index

According to the trend graph of Data Envelopment Analysis (DEA) index values for each ring period in China, according to the trend graph, it can be seen that the average rate 
of growth of the total factor of environmental pollution control efficiency in China since 2010 is about 1.043 , that is, the average annual growth rate of the total factor of environmental pollution control is $4.3 \%$, and the growth rate is low, which is affected by the combination of technical progress efficiency, technical efficiency, pure technical efficiency, and scale efficiency, as shown in Table 3.

Table 3

Tobit regression analysis results

\begin{tabular}{|c|c|c|c|c|}
\hline Express & Coefficient & Standard Error & T & Probability \\
\hline GDP (Gross Domestic Product) & 4.74 & 9.78 & 2.38 & 6.52 \\
\hline INS (Industrial structure) & 12.23 & 1.12 & 10.79 & 11.66 \\
\hline FD (Financial development) & 6.37 & 6.01 & 13.57 & 3.24 \\
\hline RD (Research and Development) & 7.91 & 14.73 & 8.16 & 3.93 \\
\hline FDI (Foreign Direct Investment) & 6.19 & 11.34 & 7.76 & 3.84 \\
\hline
\end{tabular}

To eliminate the influence of the original data characteristics on the empirical results, some of the absolute data were logarithmically processed. The results of descriptive statistics show that the difference between the extreme values of each variable is small, basically within two digits, and the skewness value of each variable is small and the kurtosis value is large, which indicates that the normal symmetry of the sample data is better and the normal peak is more obvious. The results of descriptive statistical analysis of each sample data after processing are shown in Figure 7.

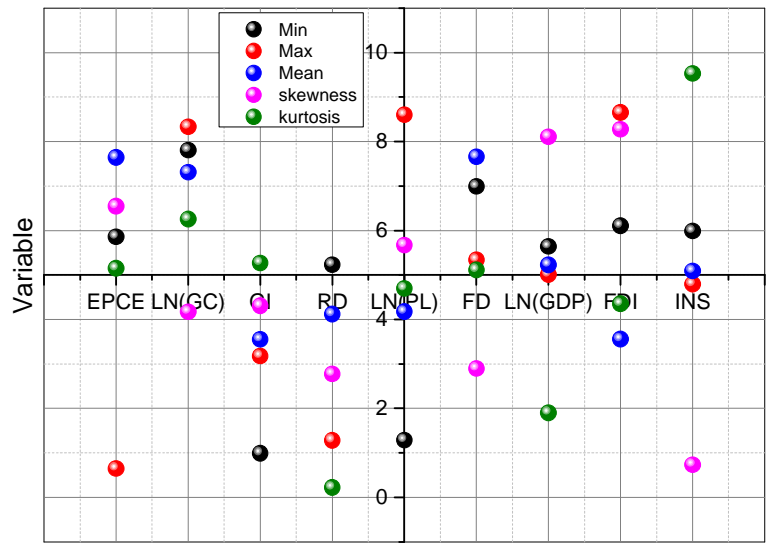

Fig. 7. Statistical results

The average annual growth rate of all elements of environmental pollution control is $4.3 \%$, which is a low growth rate, which is formed by the comprehensive influence of technological progress efficiency, technical efficiency, pure technical efficiency, and scale efficiency. The data are standardised to reduce the effect of heteroskedasticity. According to the regression results, the threshold values of $R \& D$ expenditure intensity are $0.177,0.398$ and $0.174,0.528$, and the threshold values of patent applications granted per capita are $0.596,0.612$, and 0.198 , all of which are within the $95 \%$ confidence interval and the likelihood ratio is less than the threshold value at the $5 \%$ significance level, and 
the threshold estimates are valid. The regression results were analysed by taking the single-threshold model as an example, and the regression results are shown in Figure 8.

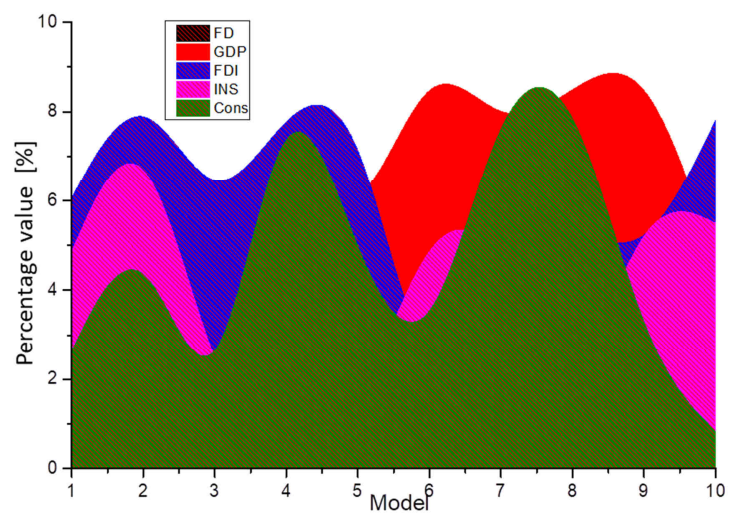

Fig. 8. Threshold model estimation results

When the R\&D expenditure intensity is below the threshold value of 0.177 , green credit has a positive impact on pollution control efficiency with a significance level of $10 \%$, indicating that green credit improves environmental pollution control efficiency when the technological progress is low, because the low level of technological progress is not enough to affect the environmental carrying capacity, and the black industry does not produce scale effect, so it is not enough to affect environmental pollution control efficiency. When the R\&D expenditure intensity is higher than the threshold value of 0.177 , green credit harms pollution control efficiency with a significance level of $5 \%$, which indicates that green credit reduces environmental pollution control efficiency when the technological progress is high, reflecting the scale effect of technological progress on environmental pollution control efficiency. According to the actual situation of its own development of carbon finance and low-carbon agriculture, it can formulate policies related to resource conservation, circular development, green economy, etc., and adopt restrictive policies for enterprises and projects with high environmental pollution and high greenhouse gas emissions. When the intensity of $R \& D$ expenditure is lower than the threshold value of 0.174, green insurance harms the efficiency of environmental pollution control at a significance level of $5 \%$, indicating that green insurance reduces the efficiency of environmental pollution control when the technological progress is low; when the intensity of $\mathrm{R} \& \mathrm{D}$ expenditure is higher than the threshold value of 0.174 , green insurance has a positive effect on the efficiency of environmental pollution control at a significance level of $1 \%$, indicating that the technological progress is higher.

If the integrated technical efficiency of a decision unit in the sample is less than 1 , this situation can be referred to as integrated technical inefficiency, which indicates that the production activities of this decision unit are not on the effective production frontier, in which case the production efficiency can be improved by adjusting the level of factor inputs or optimising the level of management and technology. From the perspective of specific values, the integrated technical efficiency is equal to the product of pure technical efficiency and scale efficiency. It indicates the comprehensive efficiency of ecological and environmental protection investment from 2010 to 2020, and the result shows that the 
average value of comprehensive efficiency of ecological and environmental protection investment is 0.877 , which is in the state of ineffective comprehensive efficiency.

\section{Conclusion}

This paper finds that except for the years 2010-2020 when the Data Envelopment Analysis (DEA) is valid, the overall efficiency of ecological environmental protection investment in other urban areas is occasionally DEA valid or generally DEA invalid, and there are large differences between regions. On average, the efficiency of ecological environmental protection investment shows a regressive trend with a decrease of $18.7 \%$ per year, and all urban areas are generally in a regressive trend, among which, Tongchuan City has the largest decrease in ecological environmental protection investment efficiency. From a regional perspective, the regression of regional ecological environmental protection investment efficiency is relatively the largest, and the regression of regional ecological environmental protection investment efficiency is relatively the smallest.

The efficiency of environmental pollution control is influenced by many factors. The industrial structure and the level of opening to the outside world can improve the efficiency of environmental pollution management, but the effectiveness of the role is low and there is still more room for development and improvement. Scientific and technological progress can alleviate the environmental pollution dilemma at the root, but there is no scientific and systematic guideline standard and way to identify green technology projects in terms of financial investment. China's economic development concept has not been fully transformed, and the level of economic development needs to be further improved. The development of green finance in China is immature, the development of green projects is still in the exploration stage, the efficiency of investment in environmental pollution management is low, the docking channel between green finance and environmental pollution management is single, and there is still a large space for integration development, i.e., diversified three-dimensional docking and large-scale system integration development are not realised.

From the regression of the four aspects of financial support to new urbanization, the correlation between the scale and strength of financial support and new urbanization is higher, and the development of new urbanization is relatively more influenced by the scale and strength of financial support, and secondarily influenced by the structure of financial support, while the role of financial support efficiency in supporting new urbanization has not yet been fully realised, and there is still much room for improvement. The correlation between new urbanization and the scale and strength of financial support is significant, with the scale and strength of financial support being more influenced by the development of new urbanization and the structure of financial support is the second most influenced by the development of new urbanization, while the "feedback effect" of new urbanization on the efficiency of financial support is still relatively weak. This also confirms the mechanism of interaction between new urbanization and financial support.

\section{References}

[1] Harlan T. Green development or greenwashing? A political ecology perspective on China's green Belt and Road. Eurasian Geography Economics. 2021;62(2):202-26. DOI: 10.1080/15387216.2020.1795700.

[2] Marszałek M, Kowalski Z, Makara A. The possibility of contamination of water-soil environment as a result of the use of pig slurry. Ecol Chem Eng S. 2019;26(2):313-30. DOI: 10.1515/eces-2019-0022. 
[3] Qu J, Wang H, Wang K. Municipal wastewater treatment in China: Development history and future perspectives. Frontiers Environ Sci Eng. 2019,13(6):88. DOI: 10.1007/s11783-019-1172-x.

[4] Zhao C, Yan Y, Wang C. Adaptation and mitigation for combating climate change - from single to joint. Ecosystem Health Sust. 2018;4(4):85-94. DOI: 10.1080/20964129.2018.1466632.

[5] Li W, Zhang P. Developing the transformation of scientific and technological achievements in colleges and universities to boost the development of low-carbon economy. Int $\mathrm{J}$ Low-Carbon Technologies. 2021;16(2):305-16. DOI: 10.1093/ijlct/ctaa066.

[6] Xia J, Li Z, Zeng S. Perspectives on eco-water security and sustainable development in the Yangtze River Basin. Geoscience Lett. 2021;8(1)18. DOI: 10.1186/s40562-021-00187-7.

[7] Yu S, Liu J, Li L. Evaluating provincial eco-efficiency in China: an improved network data envelopment analysis model with undesirable output. Environ Sci Pollut Res. 2020;27(7):6886-903. DOI: 10.1007/s11356-019-06958-2.

[8] Zhang X, Zang C, Ma H, Wang Z. Study on removing calcium carbonate plug from near wellbore by high-power ultrasonic treatment. Ultrason Sonochem. 2020:104515. DOI: 10.1016/j.ultsonch.2019.03.006.

[9] Shen M, Zhang Y, Xu H, Ma H. MOFs based on the application and challenges of perovskite solar cells. iScience. 2021;24(9):103069. DOI: 10.1016/j.isci.2021.103069.

[10] Ming LEI, Yuan X, Yao X. Synthesize dual goals: A study on China's ecological poverty alleviation system. J Integrative Agricult. 2021;20(4):1042-59. DOI: 10.1016/S2095-3119(21)63635-3.

[11] Zhong Z, Zhang X, Yang X. Benefit evaluation of energy-saving and emission reduction in construction industry based on rough set theory. Ecol Chem Eng S. 2021;28(1):61-73. DOI: 10.2478/eces-2021-0006.

[12] Ma X, Li Y, Zhang X. Research on the ecological efficiency of the Yangtze River Delta region in China from the perspective of sustainable development of the economy-energy-environment (3E) system. Environ Sci Pollut Res. 2018;25(29):29192-207. DOI: 10.1007/s11356-018-2852-y.

[13] Shuai G, Li Z, Zhang D, Elhefnawey M, Li L. On rough set theory on achieving high quality cable material production by green low carbon technology. Ecol Chem Eng S. 2021;28(1):49-59. DOI: 10.2478/eces-2021-0005.

[14] Fang C, Zhou C, Gu C. A proposal for the theoretical analysis of the interactive coupled effects between urbanization and the eco-environment in mega-urban agglomerations. $J$ Geographical Sci. 2017;27(12):1431-49. DOI: 10.1007/s11442-017-1445-x.

[15] Sołowski G, Konkol I, Cenian A. Perspectives of hydrogen production from corn wastes in Poland by means of dark fermentation. Ecol Chem Eng S. 2019;26(2):255-63. DOI: 10.1515/eces-2019-0031.

[16] Gang WX, Li LH, Hui LG. Influencing factors of eco-environmental safety of mines and their green development: A case study of Taoshan Coal Mine in Heilongjiang Province, China. Nature Environ Pollut Technol. 2020;19(2):831-8. DOI: 10.46488/NEPT.2020.v19i02.041.

[17] Liu W, Ma H, Walsh A. Advance in photonic crystal solar cells. Renew Sust Energy Rev. 2019;(116):109436. DOI: 10.1016/j.rser.2019.109436.

[18] Zhang Y, Ma H, Zhao S. Assessment of hydropower sustainability: Review and modeling. J Cleaner Production. 2021:128898. DOI: 10.1016/j.jclepro.2021.128898.

[19] Zhang X, Wu J, Liu J. Coupling coordinative development model of the economy-society-environment system in some coastal cities of the East China Sea. Polish J Environ Stud. 2020;30(1):943-54. DOI: $10.15244 /$ pjoes/122452.

[20] Ammar NR, Seddiek IS. An environmental and economic analysis of emission reduction strategies for container ships with emphasis on the improved energy efficiency indexes. Environ Sci Pollut Res. 2020;27(18):23342-55. DOI: 10.1007/s11356-020-08861-7. 